\title{
REPRESENTACIÓN E IMAGINARIO CAMPESINO
}

\section{La vida tras la mirada de un catequista \\ (Cajamarca, Perú)}

\section{Luis Mujica Bermúdez}

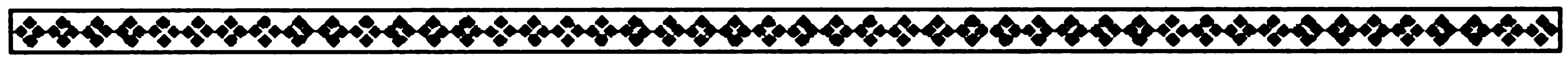

A los que mantienen la esperanza de ver un mundo de distinta manera.

LAS REPRESENTACIONES REALIZADAs por Guamán Poma de Ayala, las presentadas por Martínez de Compañón, las difundidas por los pintores de Sarhua, las pinturas de Carmelón Berrocal y de muchos otros artistas que están en el anonimato son densas formas textuales en las cuales los diagnósticos de la realidad, las denuncias o los rechazos a determinadas situaciones y las insinuaciones de utopías que se quisieran construir constituyen un tinkuy, un encuentro; vale decir, son espacios estéticos donde los trazos de las percepciones y los sentimientos, así como las pinceladas de los deseos y las expectativas, se combinan artísticamente gracias a la habilidad y la ternura del dibujante o pintor, creando un "libro abierto a los ojos de los lectores". Así como el libro de Guamán Poma, cinco siglos después,

- Este artículo, sin sus anexos, ha sido publicado en Fernando Armas Asin (Edt.), Angeli Novi, Fondo Editorial de la PUCP, Lima 2004. 


\section{LUIS MUJICA BERMÚDEZ}

aparece en los Andes solo y a su modo, un pintor chontabambino, José:Espíritu, presenta en sus poco conocidas obras no sólo una descripción de la realidad, sino también una observación crítica a la condición social del lugar donde vive; realidad que se entiende simultáneamente agonística y utópica y quizás de un modo aparentemente estático debido al encierro estético de la figura plasmada.

Es nuestra intención fundamental presentar algunas reflexiones en torno a las representaciones que el autor expone sobre su modo de ver el mundo y las relaciones sociales tomando como marco el mundo religioso. Este está conformado por las catorce estaciones de un vía crucis pintadas en cartulina con crayolas, lápices y plumones de colores ${ }^{1}$. Las catorce estaciones son representaciones o imágenes en las cuales el autor expresa con técnica inusitada la visión de la historia de la comunidad donde vive, ya que se trata de "cuadros naturales", como diría don Candelario, otro catequista del lugar. Dicho de otro modo, esta representación pictórica es una manera "estereográfica" de mostrar la complejidad de la vida donde lo político, lo religioso, lo económico, lo cultural, lo psicológico y lo estético se enhebran para dar paso a imágenes que sintéticamente presentan las concepciones y los sentimientos de una comunidad y del mismo autor. Éste, además de mostrar su propia inspiración, tuvo la oportunidad de validar su creación en un conversatorio con un grupo de sus paisanos, cuya grabación y trascripción es un documento que respalda las reflexiones que presentamos aquí. Sin lugar a dudas, el pintor hace una suerte de etnografía en su obra, es decir, se trata de una "pintura-escritura-lectura" interpretativa de la historia y de su realidad. José Espíritu es entonces un pintor-narrador que condensa en sus trazos lo que él y sus coterráneos piensan y sienten acerca de la historia, el mundo y la vida que les rodea.

El corpus de material estético que presentamos está conformado, entonces, por el vía crucis que José Espíritu ha producido y

1 Este artículo comenzó a tener cuerpo la misma tarde que Hans Meister me hizo conocer la existencia de los dibujos de José Espíritu; él mismo, días más tarde, me hizo llegar una grabación de las charlas de José y los comentarios de don Candelario y otros amigos suyos de Bambamarca. Fue una tarde de noviembre del 2001. 


\section{REPRESENTACIỚN E IMAGINARIO CAMPESINO}

donde podemos encontrar un conjunto de elementos que nos permiten proponer una hipótesis. La Iglesia católica posconciliar cajamarquina, bajo la dirección de José Dammert Bellido, obispo de Cajamarca entre los años 1962-92, ha influido en la población, sobre todo rural, en la manera de ver y entender su historia, las estructuras sociales, políticas y culturales $y$, al mismo tiempo, ha generado en un sector de sus miembros una postura crítica frente a las relaciones injustas en la zona. Para ordenar esta presentación esbozamos primero el diagnóstico como construcción pastoral de la realidad social; segundo, sobre el autor y el sentido de su obra $y$, finalmente, algunas anotaciones analíticas acerca de las visiones de la realidad histórica y social. Sé incluyen algunas reflexiones a modo de conclusión.

\section{El DIAGNÓSTICO COMO CONSTRUCCIÓN PASTORAL} DE LA REALIDAD

José Espíritu no es una casualidad, es un hombre que se ha forjado en la sociedad rural cajamarquina donde ha bebido de las aguas de la modernidad balbuciente de las últimas tres décadas del siglo XX. El pueblo de Cajamarca de José Espíritu prácticamente se ha duplicado en población en los treinta últimos años. En 1961, el departamento de Cajamarca apenas tenía 786,599 habitantes y en 1993 había crecido a 1'289,808 habitantes y a pesar de todo no dejó de ser fundamentalmente rural. En 1961 la población urbana bordeaba el 15\% y la rural el 85\%; y en 1993 la tendencia no había sufrido mayor alteración, pues el $29 \%$ era urbana y el $71 \%$ seguía siendo rural. Siendo Cajamarca fundamentalmente un departamento rural, tenía también una alta tasa de analfabetismo que llegaba al $26 \%$ y se ubicaba en la escala baja según el Índice de Desarrollo Humano (IDH) -según Eguren (1997)-, apenas por encima de Huancavelica, Ayacucho y Apurímac.

Por otro lado, Cajamarca durante los últimos treinta años ha vivido, además, sin grandes alteraciones los males económicos y políticos, donde el centralismo capitalino había seguido operando en medio de tenues tramas desarrollistas, militaristas y hasta democráticas. Cajamarca restañó apenas los procesos de modernización 


\section{LUIS MUJICA BERMÚDEZ}

a través de los ensayos de reformas agrarias, la ruptura del orden oligárquico y la aparición de movimientos populares y últimamente con la avasalladora presencia de la empresa minera. Se reemplazó la categoría indio por la de campesino para identificar a los habitantes del mundo rural. La de vecino sustituyó a la de poblador en la zona urbana, convirtiéndose aquellos, finalmente, en ciudadanos.

En este contexto, la Iglesia católica entró en proceso de transformaciones importantes. El punto de partida fue el concilio Vaticano II de 1962, que suscitó en América Latina las conferencias episcopales de Medellín (Colombia, 1968), Puebla (México, 1979) y Santo Domingo (1992). La primera conferencia episcopal marcó el inicio de una serie de reformas en la vida de la Iglesia, donde la búsqueda de la justicia aparece con una fuerza singular en el continente latinoamericano. Una corriente importante dentro de la Iglesia católica, lejos de mantenerse al margen de los procesos sociales, formó parte activa de los movimientos sociales. En la segunda conferencia episcopal se afirmó la importancia de la "opción por los pobres", como una manera específica de estar comprometida con el cambio social y político en la historia. El objetivo de esta opción estaba encaminado a la "liberación integral" (Puebla 1134ss).

Una reflexión articulada sobre el sentido de la presencia de los cristianos en la sociedad es presentada por Gustavo Gutiérrez (1971) en sú conocido libro Teología de la liberación. La propuesta de liberación articula tres niveles importantes en la vida, el nivel económico-político, el nivel de las relaciones sociales y el nivel personal. La liberación en el primer nivel se propone salir de todo aquello que constituya un obstáculo para el desarrollo y la constitución de la democracia. La liberación en el segundo nivel implica el cambio de las relaciones de discriminación y de exclusión tanto en el aspecto social y étnico como en el de género y generación. Finalmente, el tercer nivel implica el abandono de toda aquello que impida que el ser humano logre un desarrollo en el nivel personal. La reflexión teológica implicaba una cierta racionalidad y era una respuesta a las preguntas sobre el significado de la fe dentro del proceso histórico en sus formas concretas.

La Iglesia de Cajamarca no escapó a este proceso de transformaciones y estuvo presente diciendo: "Somos una diócesis rural. 


\section{REPRESENTACIÓN E IMAGINARIO CAMPESINO}

La gran mayoría de los cristianos somos campesinos... Nosotros tenemos una cultura que nos ayuda a ser humanos y cristianos. Nos damos cuenta de que nuestra cultura está en peligro. La Iglesia tiene que ser la primera en defendernos... Es todo un sistema injusto que nos desprecia y nos quiere aplastar. Pero a pesar de todos estos sufrimientos creemos que vale la pena vivir y luchar en el campo. La Iglesia tiene que seguir el camino de Cristo... Exigimos que nos respeten y que no nos quiten nuestra cultura y nuestros derechos... Nosotros queremos una Iglesia que viste poncho y sombrero" (Aporte a Puebla: 1978, junio) ${ }^{2}$. Este texto, sin duda, presenta sucintamente la manera de ver la condición humana, la situación cultural, la condición económica y también la política. De hecho, constituye una suerte de "diagnóstico pastoral", es decir, una manera de ver "la realidad" y que debería ser cambiada o transformada con la intervención de los diversos agentes sociales. En esta perspectiva la Iglesia cajamarquina quiso proponer un trabajo permanente $y$ participativo de todos los miembros involucrados en la tarea eclesial. La mirada hacia la realidad era necesaria con el objetivo de aminorar o eliminar el problema; el resultado era un conjunto de representaciones sobre la persona humana y las condiciones sociales, económicas y culturales en las que vive.

De hecho, la realidad cajamarquina no solo estaba implantada en una abrupta geografía, sino además en un sistema injusto que religiosamente mostraba deficiencias en la formación doctrinal por la escasez de agentes pastorales que asumieran las tareas educativas y sociales. En primer lugar, la realidad construida por el diagnóstico pastoral mostraba a Cajamarca como una zona en medio de dilatados territorios con valles y montes entre los dos y los cuatro mil metros de altura sobre el nivel del mar. Era considerada además como pobre por causa de un excesivo centralismo económico-político, arrinconada por el olvido, la discriminación y el abuso, problemas que se agudizaron en los últimos años (Foncodes 1994). La pobreza era vista como una consecuencia de "la civilización occidental (que) avanza sobre el ambiente andino y deteriora sus cos-

2 Ver la revista Páginas 16-17 (1978) 39-42, bajo el título general "En el camino a Puebla". 


\section{LUIS MUJICA BERMÚDEZ}

tumbres, extendiendo el egoísmo de las ciudades a la campiña... la civilización ha introducido su egoísmo y otros usos..." (Dammert 1976, s/m).

Por lo tanto, la pobreza no era un producto fortuito, antes bien tenía raíces históricas y responsabilidades políticas y técnicas, que se expresaban en el asistencialismo impuesto por políticas económicas. A esta descripción hay que añadir las diversas formas de discriminación social y los mecanismos de exclusión social del campesino y la de la mujer. La situación, lejos de superarse, se agravaba y al final de su mandato Dammert, por ejemplo, llegó a decir: "La gravísima crisis social, económica y política por la que atraviesa el Perú repercute fuertemente en nuestra zona aumentando la pobreza, el desempleo, sobre todo juvenil, y las posibilidades de auto financiación son cada vez más lejanas" (1991, noviembre).

El otro aspecto diagnosticado señalaba el centralismo gubernamental y las actitudes de los gobernantes, que dificultaban el progreso por su poca posibilidad de comprender la realidad y el malgasto de recursos nacionales. Este centralismo, además de ser inoperante, despertaba un "temor reverencial de (los) que están poseídos los funcionarios locales, frente a las manifestaciones del Gobierno central" (Dammert 1970, mayo). En una palabra, la zona se presenta convertida en la cenicienta del país ${ }^{3}$. La observación pastoral sobre las autoridades las muestra no sólo como un sistema torpe e incapaz de demarcar los campos de acción, sino también como expresiones de un caciquismo rastrero que obstaculizaba el desenvolvimiento de la zona, junto con la violencia política, que en Cajamarca tuvo diversas expresiones sobre todo al sur de la diócesis. Sin embargo, desde la visión pastoral, las organizaciones campesinas (especialmente las rondas) eran consideradas como una defensa frente a los que querían imponer la lógica de la violencia

3 Dammert, José: "La sierra norte del Perú",1972 (febrero), artículo muy difundido, donde dice "la experiencia de diez años de trabajo en la zona me impulsa a concluir que esta región es la cenicienta del país, y que siempre es dejada en el olvido. Ningún proyecto de desarrollo de la región fue incluido en el paquete presentado por el Ministro de Economía y Finanzas al Banco Internacional; y esta ausencia es solo el eslabón de una larga cadena". 


\section{REPRESENTACIÓN E IMAGINARIO CAMPESINO}

política. A pesar de todo, la violencia política había desorganizado la vida campesina y aumentado la desconfianza y sospecha en los diversos medios, incluido el religioso, colocando a "los campesinos entre la espada y la pared, porque las fuerzas del orden no se portan bien, sino que cometen muchos abusos". El diagnóstico pastoral, por lo tanto, arrojaba no sólo una mirada crítica sino también denunciaba la pobreza, el abandono, la violencia, la discriminación de los pobres y el abuso por parte de los potentados, las autoridades centrales y locales. Si había pobres y pobreza era por razones de injusticia con raigambre histórica, por formas estructurales y por voluntades humanas.

En segundo lugar, el diagnóstico pastoral afirma que la población sufría una "ignorancia religiosa" y la Iglesia una "debilidad institucional". La "ignorancia religiosa" se explicaba por los procesos en la evangelización, que "predicaron verdades y principios católicos, pero la esencia del cristianismo, la adhesión a la persona de Cristo, quedó cubierta por el ropaje del catolicismo de la contrarreforma, y el Hijo de Dios no tiene el papel fundamental que le compete en la Iglesia" (Dammert 1973, noviembre). Sin embargo, el pueblo cajamarquino es religioso y ritualista y las fiestas patronales son mantenidas y organizadas por la población y la actuación del sacerdote es marginal, a tal punto que es considerado como "un extraño que desempeña un papel preponderante, pero que no se asimila al pueblo" (Dammert 1973, noviembre). Desde la perspectiva del concilio Vaticano II, la situación cajamarquina era vista como crítica y dicotómica, donde había un divorcio entre fe y vida que se expresaba no solo en desconocimiento de la doctrina de la Iglesia sino también en el incumplimiento de las obligaciones sociales que emanan de ella. Al fin y al cabo, la ignorancia religiosa consistía en una inadecuada o deficiente instrucción en la doctrina cristiana y social, carente de convicciones y de compromiso con la sociedad. Los vacíos en la formación de los cristianos se debían fundamentalmente a los procesos de catequización; es decir, a la "falta de (una) evangelización a fondo" (Dammert 1965, agosto).

Se evalúa, por otra parte, que las estructuras eclesiásticas de la Iglesia en la sociedad cajamarquina no responden a la realidad pastoral, por razones legalistas y prácticas. "Las estructuras ecle- 


\section{LUIS MUJICA BERMÚDEZ}

siásticas - dice Dammert- no responden a la realidad pastoral actual, y a mi parecer en América Latina nunca se adecuaron debidamente por haber sido simplemente transportadas y no arraigaron. Provincias eclesiásticas, diócesis y parroquias tienen armazones ficticios y los obispos y sacerdotes nos sentimos enmarcados dentro de un sistema que no satisface absolutamente" (1971, octubre). A esto se debe sumar la organización eclesial bajo el sistema de parroquias, insuficiente para responder a contextos como el cajamarquino. El "parroquialismo" profundizaba la debilidad de la institución por la escasez de agentes pastorales, que generaba otro problema como el de la concentración del poder bajo la forma del "clericalismo", que era aceptado culturalmente incluso por la población.

La vida de la comunidad de los fieles estaba muy centrada en la iniciativa del sacerdote y sus roles se habían reducido al servicio de las prácticas rituales. La revisión de la realidad en la que se evangelizaba llegaba a la constatación de una fragilidad institucional de la base local, debido a que no había una suficiente formación actualizada y había pocos agentes pastorales que pudieran responder a los requerimientos de la pastoral. Sin embargo, esta sucinta descripción o construcción discursiva de la realidad tenía como objetivo el transformarla y para esto se propone un plan de acción pastoral que considera el cambio social, la insistencia en la formación o educación y la constitución de organizaciones sociales de base reales.

En primer lugar, el plan pastoral no pretendía iniciar como tabula rasa, desconociendo la experiencia anterior. "No comenzamos de cero -dice Dammert- y no podemos ignorar lo realizado hasta ahora o condenarlo sin más como algo mal hecho" (1973, octubre). Reconoce los errores por desconocimiento de la realidad, por aplicación de objetivos y métodos extraños. El deficiente funcionamiento de las estructuras eclesiásticas requería de un replanteamiento de sus prioridades pastorales que implicaba a su vez superar la "ignorancia religiosa", desarrollando un plan de "re-evangelización" y haciendo que los miembros laicos sean también agentes pastorales locales.

No se quería que la organización eclesial fuera una copia o un trasplante de otras experiencias, sino que se buscaba "adaptar" 


\section{REPRESENTACIÓN E IMAGINARIO CAMPESINO}

la idea y crear una comunidad cristiana en la realidad cajamarquina, formarla desde las necesidades y las capacidades de la gente del lugar, y tomando en cuenta que no debía identificarse comunidad eclesial con parroquia. Una comunidad cristiana debería estar ordenada por una manera de vivir y organizar una misión y por un conjunto de prácticas, donde se pueda leer y reflexionar en torno a la Biblia, compartir y discutir los problemas que afectan a sus miembros y a la colectividad y coordinar tareas en beneficio de otros a través del método ver-juzgar-actuar, propiciando la participación en los diversos niveles de la vida social. Esto significaba que los miembros que participaban dejaban de lado el anonimato y el ninguneo, al que habían sido mantenidos por diversas razones, para pasar a ser sujetos capaces no sólo de participar en la constitución de su comunidad sino ser agentes activos en la sociedad mayor.

La formación de las comunidades eclesiales debía basarse en el principio de que nadie debía sentirse extraño y las ya existentes, de hecho, han ido constituyéndose con limitaciones tanto en el campo como en la ciudad. En ésta, generalmente estaban conformadas por los movimientos apostólicos especializados de profesionales, estudiantes o por grupos adscritos a parroquias bajo la modalidad de cofradías u otras agrupaciones. En la zona rural, las comunidades estaban constituidas por campesinos que tenían como dirigentes religiosos o catequistas nativos en las zonas más alejadas. La comunidad cristiana era, entonces, un concepto a-espacial y cualitativo, en la medida en que estaba constituida por grupos humanos que se reunían para evaluar la situación en que viven, confrontarla a la luz de la Biblia y trazar las tareas de compromiso en la localidad.

Por otro lado, la evangelización que había recibido una gran masa campesina requería de una profundización de la fe a través de "re-evangelización", esto implicaba combatir la ignorancia a través de un programa múltiple y adecuado y cuyo objetivo era que las personas tomaran conciencia de su dignidad y de su participación sin subordinarse a nadie. La re-evangelización, pues, debía ensayar innovaciones y no imponer un sistema y la enseñanza debía ser personal, total y actual. Personal en la medida en que las verdades religiosas deben llevar a un encuentro personal entre Dios y la per- 


\section{LUIS MUJICA BERMÚDEZ}

sona humana. Total en tanto la salvación busca la adhesión integral a un Dios interesante y apasionante. Actual en la medida en que las palabras deben tener sentido y tomar en cuenta las categorías intelectuales de los auditores. La re-evangelización consideraba, entonces, la posibilidad real del diálogo con los otros y la formación de un habitus y no una mera reproducción social o cultural.

Con el tiempo la prédica y la acción habían caído en un terreno apropiado y habían calado en el despertar de la conciencia religiosa y social del campesinado, que se expresaba en el rechazo de una situación de opresión, marginación y discriminación, y en el descubrimiento de sus potencialidades y capacidades. De este modo, el campesino re-descubre su "filiación divina" y su "fraternidad con los demás hombres" y se organiza para luchar en contra de la injusticia y las desigualdades existentes. Se levanta su dignidad como persona para hacer frente a las actitudes de desprecio y explotación. La re-evangelización se había encaminado a "abrir los ojos" y hacer saber las potencialidades de los campesinos. Dammert dice, por eso, que la re-evangelización debía continuar mediante la formación sobre todo del mundo laico del campo y de la ciudad y que formen parte de comunidades eclesiales sociológicamente fuertes. Esto requería necesariamente de liderazgos locales igualmente fuertes y la Iglesia cajamarquina se propuso capacitar y especializar a los laicos para diversas funciones, mediante la enseñanza de la doctrina de la Iglesia y la administración de algunos sacramentos. Esta sería una manera de enfrentar las restricciones geográficas y los condicionamientos culturales con raigambre histórica.

La formación de agentes locales se incrementó y por lo tanto también creció el número de dirigentes religiosos inmediatos, tratando de superar las concepciones jerárquicas excluyentes y promoviendo la participación en diferentes estamentos de la sociedad. En una palabra, se trataba de militantes seglares que debían ser el fermento cristiano en los diversos ambientes. La formación de los nuevos agentes debería superar la concepción dicotómica de la realidad y una mentalidad jerarquizada y excluyente. Estos planteamientos significan que debían superarse algunas deficiencias con tal de "despertar en los laicos la conciencia de su responsabilidad de la Iglesia". De este modo se vislumbraron nuevos ministerios sin 


\section{REPRESENTACIÓN E IMAGINARIO CAMPESINO}

desplazar a los sacerdotes y religiosas y que al mismo tiempo pudieran cumplir roles y funciones complementarios en la marcha de las comunidades cristianas. La formación debería ser en todos los niveles y grados, pero con un objetivo muy concreto: hacer que la gente pueda valerse por sí misma y pueda participar activamente de su organización y destino.

La formación dada a los laicos y sobre todo a los campesinos se logró concretar en octubre de 1970, cuando el obispo delegaba oficialmente ad experimentum en tres catequistas campesinos las funciones de administrar el sacramento del bautismo en forma ordinaria con el permiso del papa Pablo VI. Esta concesión fue renovada y extendida por la Sagrada Congregación de Sacramentos a todo el Perú. Esto significaba que los roles asignados para los sacerdotes y religiosas deberían reducirse a "lo estrictamente esencial", desprendiéndose de tareas no "específicamente espirituales". La ayuda de los misioneros extranjeros constituía sobre todo un remedio transitorio a corto plazo (1969, abril); no se trataba de excluirlos, sino de valorarlos y que su inserción en el terreno de la pastoral debía ser previo conocimiento de la situación coyuntural.

En una palabra, el diagnóstico pastoral arrojaba una sociedad cajamarquina tradicional cuyas relaciones sociales siguen siendo tributarias del colonialismo, con una débil formación religiosa y escasez de sacerdotes. Esto requería, por tanto, la construcción de estructuras autóctonas, la realización de una re-evangelización y la preparación de los laicos para hacer frente el problema de manera eficaz.

\section{EL AUTOR Y EL SENTIDO DE SU OBRA}

José Espíritu ahora es un ciudadano, campesino, rondero, catequista $y$ artista pintor de la comunidad de Chontabamba, del distrito de Bambamarca, provincia de Hualgayoc, Cajamarca. Es un ciudadano orgulloso de haber descubierto su identidad como parte de un país y de un mundo con una historia que trasciende sus propios parajes, en la medida en que reconoce para sí un conjunto de derechos y que éstos permanecen conculcados de algún modo. Este ciudadano es consciente de que es un campesino parcelero, pero 


\section{LUIS MUJICA BERMÚDEZ}

pobre. Es propietario de un trozo de terreno y un hato de ganado que produce lo necesario para que él y su familia puedan mantenerse y subsistir. Es consciente de que su pobreza no está dada por obra del destino, sino que es consecuencia de diversos factores externos e internos. Desde hace muchos años, ante la presencia de ladrones y abigeos, su comunidad ha creado una organización "rondera" que tiene como objetivo defender los pocos medios de subsistencia que tienen las familias de esas zonas y hacer la "justicia campesina". Es además miembro de una comunidad y catequista de una vasta zona en la que imparte las enseñanzas de la fe cristiana y ayuda a los miembros a mantenerse con una mirada atenta y crítica frente a la adversidad y los sistemas económicos y políticos que medran la vida de la gente pobre y anima la esperanza a los jóvenes que han decidido quedarse en la zona. Es también un artista plástico que ha surgido de la "escuela de la vida", que ha ido aprendiendo a grabar en papeles y cartulinas su manera de entender y comprender el mundo que le rodea y la historia que quiere construir. Así, la producción plástica de José Espíritu combina en la forma la oralidad y lo pictórico y se ubica en la perspectiva agonística de Guamán Poma y la propuesta de la teología de la liberación, pero dentro del marco de la religiosidad popular.

En primer lugar, el vía crucis de José Espíritu es una representación dé la complejidad comprensiva de la sociedad cajamarquina. De la Torre había hecho ya una lectura comprensiva del cosmos cajamarquino al decir que se trataba de un modo de organizar conceptualmente el conjunto del mundo natural en una comunidad (1986: 11). Carmelón Berrocal Evanán, un artista plástico ayacuchano, al decir de Macera, era un nuevo Guamán Poma del siglo XX que exploró la narrativa, pero "normatizada" por el mismo Macera para fines educativos: "La programación de los textos y dibujos era conversada preliminarmente por mí con Carmelón Berrocal" (Marcera 1999: 11). Berrocal era un hombre de frontera entre la oralidad quechua y la escritura española, entre la plástica andina y las convenciones occidentales. Se podía entrever en su producción una heteroglosia conflictiva que define al Perú como un país quechuañol. Sin embargo, la producción de Berrocal se encuentra subordinada a un modelo de modernización que afecta a la 


\section{REPRESENTACIÓN E IMAGINARIO CAMPESINO}

"totalidad de las artesanías" en su volumen productivo y a los circuitos de comercialización, a las formas y a la institucionalidad estética o a la significación cultural. Se trata de una descripción lineal de la naturaleza y de las "costumbres" de una comunidad. El mapa, el trabajo agrícola y textil, las plantas, los animales, la flora, la fauna, así como los peces, son la especialidad de Berrocal. En el mismo estilo de los dibujos de Felipe Guamán Poma y las llamadas tablas de Sarhua, los dibujos de José Espíritu son cuadros que tienen un texto explicativo precedidos por un título. Este texto está escrito en un lenguaje simple, con problemas de sintaxis y lleno de errores ortográficos y de puntuación; sin embargo, vale anotar que la trasgresión a las reglas gramaticales y ortográficas forman parte del documento de Bambamarca. Así, la producción de José Espíritu, a diferencia de la de Berrocal, la que aparentemente está en la línea de Martínez de Compañón, tiene una mirada agonística de la realidad, hay una constatación de una condición social, económica, política y religiosa como producto y efecto de hechos, por lo que en esta perspectiva su producción está más cerca de la de Guamán Poma.

La imagen ha sido el lenguaje predilecto en el mundo andino. Oralidad e imagen son dos modos de trasmitir la visión del mundo y además son formas de presentar una interlocución. Las qellcas andinas (Nolte 1991), en tanto describen y analizan las nuevas relaciones en el mundo contemporáneo, hacen conocer la vida de la gente como una continuidad en el tiempo. Es probable que la combinación del dibujo y lo escrito no sea sino una forma de afirmación de una idea que quieren transmitir tanto a sus lectores conocidos como desconocidos. Además del material gráfico y el texto, la obra de José Espíritu ha sido comentada 4 , es decir, existe una grabación donde los miembros de su comunidad y colegas catequistas de José explican lo que significan los gráficos y subrayan con la palabra el sentido mismo de su modo de ver el mundo y sus relaciones.

Las catorce imágenes del vía crucis constituyen el corpus, pictórico y literario dialogado del pensamiento y sentimiento de un sector importante de los campesinos de Bambamarca y, por am-

4 Anexo 2 de este artículo. 


\section{LUIS MUJICA BERMÚDEZ}

pliación, de los campesinos de la zona norte de Cajamarca. Dicho corpus es un "lenguaje" configurado que contiene mensajes que requieren de una interpretación minuciosa. La producción pictórica tiene una unidad imaginativa con una trama muy conocida y una gama de sentimientos y percepciones que se consolidan en una única imagen, en una historia, en tanto que "las representaciones constituyen la esencia de la comunicación humana, de la cultura humana" (Goody 1999: 18). El sentido de la representación es traer al presente algo ausente, $y$ al mismo tiempo se trata de construir una manera de concebir y buscar implícitamente el horizonte utópico del contexto que se presenta. Por ello, la definición de Goody nos da las pautas necesarias para entender la unidad cognitiva manifiesta en las catorce estaciones: "La representación significa presentar de nuevo, la presentación de algo que no está presente, pudiendo adoptar una forma tanto lingüística como visual" (Goody 1999: 47).

De hecho, representar es hacer presente lo que está ausente, no se trata de una réplica o una copia de lo que no está ahora; tampoco es una sustitución de lo que debería estar; y menos aún se trata de una transposición de lo no existente a una existencia. La representación implica la elaboración de una manera de entender el mundo y de sus formas de relación. Muchas veces esta representación puede ser conflictiva y acarrear una "guerra de imágenes" (Gruzinski 2001), sobre todo si esa manera no coincide con "la" manera de ver la realidad o la historia de otros. Sin duda, la representación de José Espíritu puede resultar ambivalente, si no ambigua. Ambivalente en tanto los rasgos construidos tienen una doble valoración y pueden resultar en sí mismos una contradicción y generar un conflicto desde las diversas posiciones de lectura. Y ambigua en tanto que las lecturas que se hagan del texto no tienen un valor específico para las partes que la leen. Pero la mirada de José Espíritu descubre una serie de conflictos que son representados, los que pueden llegar a causar, a su vez, un conflicto de sensibilidades, a esto nos referimos cuando hablamos de una representación agonística.

En segundo lugar, José Espíritu, como creyente y catequista, se ubica dentro de una "Iglesia del día" en oposición a una "Iglesia 


\section{REPRESENTACIÓN E IMAGINARIO CAMPESINO}

de la noche" (ver imágenes en el anexo). La "Iglesia de noche", identificada por la luna en la parte izquierda, es concebida como piramidal y jerárquica, dividida en ocho escalones. En el primer nivel se ubica la gente de rodillas ante la imagen piramidal en la que los "alumnos del seminario" son en realidad los que forman la primera escalinata, aunque están en el mismo nivel. Los diez "alumnos del seminario" tienen un libro en la mano izquierda y están vestidos de manera diferente a los campesinos. En el segundo nivel se encuentran ocho "diáconos" varones, dos de ellos tienen anteojos y todos siguen portando un libro y un cambio ligero en la vestimenta. En el tercer nivel hay siete "sacerdotes", con su clásica vestimenta ritual, cinco de los cuales tienen una cruz; todos tienen un cáliz en la mano izquierda y tres de ellos llevan anteojos. En el cuarto nivel hay cinco "obispos" vestidos de manera similar, todos llevan anteojos, un solideo, una capa y una túnica blanca; además tienen un báculo y una cruz en el pecho. En el quinto nivel hay tres "arzobispos" con vestimenta semejante a la de los "obispos", diferenciándose de los anteriores por llevar una mitra en la cabeza. En el sexto nivel se ubican dos "cardenales" con un báculo más grande que el de los anteriores, las mitras llevan una cruz y no están en el pecho como en los anteriores. En el séptimo nivel se encuentra el "nuncio" solo, con dos cruces y el báculo más pequeño. Finalmente, en el último nivel se encuentra el "Papa" sentado, dentro de una urna, con un libro en la mano izquierda y el báculo en la mano derecha.

Los únicos que tienen la "palabra" en esta estructura son los que están en los distintos niveles o escalones. Los primeros dicen en plural "nosotros somos los alumnos del seminario"; los segundos, en la voz de uno de ellos, dicen: "los diáconos esperamos la ordenación de nuestro jefe para pasar a pertenecer a la Iglesia"; uno de los del tercer nivel dice: "nosotros los sacerdotes sólo cumplimos lo que nuestro jefe nos ordena, pues ustedes laicos y pueblo arrepentido confiesen sus pecados, reconcíliense con Dios"; los siguientes, en primera persona, dicen: "soy el obispo, el superior jefe espiritual, puedo hacer lo que quiero en mi diócesis", el siguiente vuelve a decir en plural: "somos arzobispos, de nosotros dependen todas las prelaturas y las diócesis"; los de más arriba dicen: "somos los cardenales. Nosotros conformamos el consejo papal"; el penúltimo dice: 


\section{LUIS MUJICA BERMÚDEZ}

"soy el nuncio, el representante y mensajero del papa"; finalmente, el último dice: "soy el Papa, el sumo pontífice romano".

En cambio la imagen que representa la "Iglesia del día" tiene, en primer lugar, un recuadro con un texto que a la letra dice: "Baticano II, Medellín, Puebla, siguiendo el ejemplo auténtico de Jesús. En esa forma, algunos obispos intentaron trabajar con la jente. Con la opción de conseguir la liberación de los pobres, los oprimidos. Proclamando justicia para los maltratados e indefensos. Pero como a Jesús lo mataron igual. Siguen haciendo con sus seguidores tal como monseñor Oscar Romero". En segundo lugar, la imagen es horizontal y al centro de todos aparece Jesús con una vestimenta de "estampita", común al mundo religioso popular. En una primera esfera inmediata están cinco "obispos" con anteojos y con sus respectivos solideos en la cabeza, rodeando a Jesús. En una segunda esfera, mucho mayor y sin ningún orden, aparecen, en un primer plano, entre los campesinos, algunos "obispos", "sacerdotes" y diminutas "religiosas" muy cerca de los lisiados y de los niños. En medio de los campesinos están también presentes "algunas personas" que no tienen sombrero o con un gorro, con anteojos pero con poncho; estos representan a "extranjeros" o "limeños identificados con el pueblo". En un segundo plano hay dos grupos importantes, uno a la derecha, que dirige la mirada hacia el centro; en cambio, el otro grupo, el que está la izquierda y de espaldas al público, está mirando al sol. En estos dos grupos las personas no llevan sombreros, por lo que no pueden ser identificadas como campesinos.

La producción artística de José Espíritu, en suma, representa con claridad una lectura política, económica, social, religiosa y cultural de la sociedad donde vive. Por ello, nuestra hipótesis central es que los campesinos, durante los últimos treinta años, han ido cambiando su forma de ver el mundo y las relaciones sociales. Por ello el texto pictórico y escrito, al que añadimos los comentarios orales sobre el tema, constituyen un documento importante para dar cuenta de la lectura de la historia y las relaciones sociales en un sector de la sociedad cajamarquina y cuyo principal motor han sido los miembros de la Iglesia en las diversas etapas, tal como lo reconoce Gitlizt (1996), Osorio (1998), Mujica (2000) y Klinger-KnechtFuchs (2001). 
De hecho, los dibujos de José implican una producción intelectual que tiene una raigambre teológica que Hugo Echegaray recordara comentando el libro Vamos caminando (1977), producido en el contexto de la Iglesia cajamarquina y que sin lugar a dudas ha influido en la vida intelectual campesina, rondera y catequista durante los últimos treinta años del siglo XX. Así, como la introducción de dicho libro decía: "Si quieren buscar su liberación juntamente con Cristo, capaz este libro les pueda ayudar", ahora también podría decirse que "capaz estos dibujos les puedan ayudar". De esta manera, la creación de José Espíritu entra en la perspectiva de la teología de la liberación, es decir, en el horizonte que la Iglesia católica realizó a través de una intensa labor pastoral en dicha región norteña, sobre todo con el apoyo de José Dammert -obispo emérito de la diócesis de Cajamarca- quien se constituyó como una de las principales autoridades y que se preocupó por el desarrollo integral de los campesinos.

José Espíritu tiene su propia aspiración y propuesta. Se ubica en un camino que pretende superar una dicotomía cultural que no permite sobreponer la relación entre el campo y la ciudad y, al mismo tiempo, mostrar las aspiraciones del campesinado y de los pobladores de las zonas urbano-marginales. Ansía, del mismo modo, presentar alternativas que conduzcan hacia una sociedad de paz y justicia. Esta intención, sin embargo, se encuentra en tensión entre la opresión y la liberación. De algún modo participa de la perspectiva de la teología de la liberación, en tanto ésta es una reflexión sobre Dios desde la acción de los pobres que luchan por salir y liberarse de la explotación económica, política, ideológica y cultural que oprime y deshumaniza; y presenta a un Jesús "liberador" de las diversas dimensiones de la vida humana y como un campesino vestido con poncho, sombrero y ojotas. De este modo, José Espíritu construye un paradigma de pensamiento y acción con el que quiere identificarse.

En tercer lugar, como campesino con una tradición añeja, no podía abandonar de la noche a la mañana lo que había sido el sostén de su misma cultura. José, como autodidacta, había desarrollado algunas obras y había contribuido en la parte grafica de la revista semanal El Despertar, de la parroquia de Bambamarca, 


\section{LUIS MUJICA BERMÚDEZ}

durante más de 15 años. Aunque la actividad artística de José Espíritu se desarrolla "a pedido", como los cuadros del vía crucis, que fueron realizados a solicitud de "los amigos de Bambamarca" (Alemania), con la finalidad de hacer conocer la "realidad" de la vida de la Iglesia cajamarquina en "otros" lugares. Así como el mundo rural era el espacio de sus movimientos, la religiosidad era el espacio donde José se entendía como persona; así, el "arte religioso" no viene a ser sino una encrucijada, una realidad social compleja y llena sorpresas, a través de las cuales José quiere mostrar su ciudadanía.

Para la tradición cristiana el vía crucis es una de las expresiones del sentido religioso del pueblo creyente y el objetivo de las expresiones es la de prolongar la vida litúrgica de la Iglesia (Catecismo $\left.N^{\circ} 1674-5\right)$. El vía crucis de José Espíritu es una encrucijada de datos polisémicos. Es un lenguaje complejo construido por su autor en tanto que es una interpretación de la historia y de las relaciones sociales dentro de ella, pero también es como una proposición y una perspectiva de solución a los problemas sociales que viven y cuestionan. "La imagen puede ser el vehículo -dice Gruzinski-de todos los poderes y de todas la vivencias. Aunque lo sea a su propia manera. El pensamiento que desarrolla ofrece una materia específica tan densa como la escritura aunque a menudo es irreductible a ella" (2001: 13).

La influencia de la Iglesia tradicional en el mundo rural de Cajamarca no podía pasar desapercibida en la mentalidad de José. En el libro Celebraciones. Pastoral rural. Cajamarca, reeditado por la diócesis de Cajamarca en 1994 (154-205), en su sexta edición, aparecen dos tipos de vía crucis: uno "tradicional" y el otro "bîblico". Sea dicho de paso, así como Vamos caminando era un libro de reflexiones, el libro de las "celebraciones" constituía un manual imprescindible para la vida litúrgica de las comunidades. Para nuestro caso, la base del vía crucis donde se inspira José Espíritu es la bíblica, claro está, desde una óptica campesina. El esquema comparativo del marco que luego analizaremos es como sigue (ver cuadro de vía crucis): 


\section{VÍA CRUCIS}

\begin{tabular}{|c|c|c|c|c|}
\hline \multirow[t]{2}{*}{$\mathbf{E}$} & \multirow[t]{2}{*}{ Tradicional } & \multirow[t]{2}{*}{ Bíbulco } & \multicolumn{2}{|r|}{ CAMPESINO } \\
\hline & & & AYER & "HOY ACTUALMENTE" \\
\hline 1 & $\begin{array}{l}\text { Jesús con- } \\
\text { denado a } \\
\text { muerte }\end{array}$ & $\begin{array}{l}\text { Jesús toma } \\
\text { última cena } \\
\text { discípulos }\end{array}$ & $\begin{array}{l}\text { Última cena } \\
\text { con } 12 \text { ami- } \\
\text { gos más co- } \\
\text { nocidos }\end{array}$ & $\begin{array}{l}\text { "Compartición" a pesar de } \\
\text { pobreza. En fiesta no hay } \\
\text { discriminación. }\end{array}$ \\
\hline 2 & $\begin{array}{l}\text { Jesús car- } \\
\text { ga con la } \\
\text { cruz }\end{array}$ & $\begin{array}{l}\text { Agonía de } \\
\text { Jesús en el } \\
\text { huerto }\end{array}$ & $\begin{array}{l}\text { La agonía } \\
\text { de Jesús en } \\
\text { el huerto } \\
\text { "Getsemanî" }\end{array}$ & $\begin{array}{l}\text { Cristos agonizan aplastados } \\
\text { por extrema pobreza, desnu- } \\
\text { trición infantil, injusticia, ve- } \\
\text { jez prematura. }\end{array}$ \\
\hline 3 & $\begin{array}{l}\text { Jesús cae } \\
\text { por prime- } \\
\text { ra vez }\end{array}$ & $\begin{array}{l}\text { Junta } \\
\text { suprema } \\
\text { condenó a } \\
\text { Jesús }\end{array}$ & $\begin{array}{l}\text { Jesús es } \\
\text { condenado } \\
\text { a muerte }\end{array}$ & $\begin{array}{l}\text { Autoridades se creen reyes, } \\
\text { oprimen y dominan; sectas } \\
\text { y autoridades eclesiásticas } \\
\text { humillan. }\end{array}$ \\
\hline 4 & $\begin{array}{l}\text { Encuentro } \\
\text { con su ma- } \\
\text { dre }\end{array}$ & $\begin{array}{l}\text { Jesús lleva- } \\
\text { do ante el } \\
\text { goberna- } \\
\text { dor }\end{array}$ & $\begin{array}{l}\text { Llevado a la } \\
\text { autoridad } \\
\text { superior }\end{array}$ & $\begin{array}{l}\text { Pilatos que se dejan seducir } \\
\text { por culpables y cristos } \\
\text { ronderos son condenados y } \\
\text { procesados. }\end{array}$ \\
\hline 5 & $\begin{array}{l}\text { S i mó n } \\
\text { Cireneo } \\
\text { ayuda a } \\
\text { Jesús }\end{array}$ & $\begin{array}{l}\text { Maltrato } \\
\text { de Jesús }\end{array}$ & $\begin{array}{l}\text { Jesús mal- } \\
\text { tratado por } \\
\text { autoridades } \\
\text { y pueblo. }\end{array}$ & $\begin{array}{l}\text { Cristos maltratados por } \\
\text { "Pilatos" que dicen acabar } \\
\text { con violencia, pobreza y de- } \\
\text { fender democracia y la libre } \\
\text { expresión. }\end{array}$ \\
\hline 6 & $\begin{array}{l}\text { Verónica } \\
\text { limpia ros- } \\
\text { tro del Se- } \\
\text { ñor }\end{array}$ & $\begin{array}{l}\text { Le cargan } \\
\text { la cruz a } \\
\text { Jesús }\end{array}$ & $\begin{array}{l}\text { Le cargan } \\
\text { todo el peso } \\
\text { de la cruz }\end{array}$ & $\begin{array}{l}\text { Nos cargan a cada uno una } \\
\text { cruz muy pesada que es el } \\
\text { hambre, miseria, explota- } \\
\text { ción. }\end{array}$ \\
\hline 7 & $\begin{array}{l}\text { Jesús cae } \\
\text { por segun- } \\
\text { da vez }\end{array}$ & $\begin{array}{l}\text { Cirineo } \\
\text { ayuda a } \\
\text { Jesús }\end{array}$ & $\begin{array}{l}\text { "Simon Ci- } \\
\text { rineo" ayu- } \\
\text { da a cargar } \\
\text { la cruz }\end{array}$ & $\begin{array}{l}\text { En Bambamarca "existimos } \\
\text { muchísimos caídos bajo esa } \\
\text { pesada cruz sin podernos le- } \\
\text { vantar". }\end{array}$ \\
\hline
\end{tabular}


LUIS MUJICA BERMÚDEZ

\begin{tabular}{|c|c|c|c|c|}
\hline \multirow[t]{2}{*}{$\mathbf{E}$} & \multirow[t]{2}{*}{ Tradicional } & \multirow[t]{2}{*}{ Bíblico } & \multicolumn{2}{|r|}{ Campesino } \\
\hline & & & AYER & "HoY aCtualmente" \\
\hline 8 & $\begin{array}{l}\text { Encuentro } \\
\text { con muje- } \\
\text { res }\end{array}$ & $\begin{array}{l}\text { Mujeres } \\
\text { lloran por } \\
\text { Jesús }\end{array}$ & $\begin{array}{l}\text { Las mujeres } \\
\text { lloran por } \\
\text { Jesús }\end{array}$ & $\begin{array}{l}\text { Actualmente en Bamba- } \\
\text { marca las mujeres buscan li- } \\
\text { beración, pero existen mu- } \\
\text { chas dificultades. }\end{array}$ \\
\hline 9 & $\begin{array}{l}\text { Cae por } \\
\text { tercera vez }\end{array}$ & $\begin{array}{l}\text { Crucifican } \\
\text { a Jesús }\end{array}$ & $\begin{array}{l}\text { Crucifican a } \\
\text { Jesús }\end{array}$ & $\begin{array}{l}\text { El pueblo peruano sigue } \\
\text { oprimido y humillado por la } \\
\text { prepotencia de los podero- } \\
\text { sos. }\end{array}$ \\
\hline 10 & $\begin{array}{l}\text { Jesús des- } \\
\text { pojado de } \\
\text { su ropa }\end{array}$ & $\begin{array}{l}\text { Jesús salva } \\
\text { al ladrón }\end{array}$ & $\begin{array}{l}\text { Jesús per- } \\
\text { dona al la- } \\
\text { drón }\end{array}$ & $\begin{array}{l}\text { En Bambamarca hay mu- } \\
\text { chas capacitaciones, a través } \\
\text { de la Biblia se ha logrado la } \\
\text { tranquilidad. }\end{array}$ \\
\hline 11 & $\begin{array}{l}\text { Clavado } \\
\text { en la cruz }\end{array}$ & $\begin{array}{l}\text { Jesús da a } \\
\text { María } \\
\text { como } \\
\text { madre }\end{array}$ & $\begin{array}{l}\text { Jesús entre- } \\
\text { ga a María } \\
\text { como nues- } \\
\text { tra madre }\end{array}$ & $\begin{array}{l}\text { El Señor encarga el amor } \\
\text { verdadero a madrecitas a } \\
\text { esposas e hijas. }\end{array}$ \\
\hline 12 & $\begin{array}{l}\text { Muere en } \\
\text { la cruz }\end{array}$ & $\begin{array}{l}\text { Jesús } \\
\text { muere en } \\
\text { la cruz }\end{array}$ & $\begin{array}{l}\text { Jesús mue- } \\
\text { re en la cruz }\end{array}$ & $\begin{array}{l}\text { Cristos mueren fusilados por } \\
\text { policía y militares, por terro- } \\
\text { rismo; por defender justicia } \\
\text { social. }\end{array}$ \\
\hline 13 & $\begin{array}{l}\text { Jesús en } \\
\text { brazos de } \\
\text { su madre }\end{array}$ & $\begin{array}{l}\text { Entierran a } \\
\text { Jesús }\end{array}$ & $\begin{array}{l}\text { Entierran a } \\
\text { Jesús }\end{array}$ & $\begin{array}{l}\text { En territorio peruano hay } \\
\text { tres clases de ciudadano: cla- } \\
\text { se capitalista, medio y muy } \\
\text { pobre. }\end{array}$ \\
\hline 14 & $\begin{array}{l}\text { Jesús es } \\
\text { sepultado }\end{array}$ & $\begin{array}{l}\text { La resu- } \\
\text { rrección de } \\
\text { Jesús }\end{array}$ & $\begin{array}{l}\text { Resurrec- } \\
\text { ción de } \\
\text { nuestro Se- } \\
\text { ñor Jesús }\end{array}$ & $\begin{array}{l}\text { Hoy "existimos muchísimos } \\
\text { muertos en vida". Gracias a } \\
\text { Dammert, desde 1963, en } \\
\text { Bambamarca existe un ini- } \\
\text { cio de resurrección }\end{array}$ \\
\hline
\end{tabular}




\section{EL VÍA CRUCIS Y SU SIGNIFICADO}

Una vez presentado el sentido de los dibujos de José Espíritu no cabe sino analizar el contenido mismo del vía crucis. Aquí se presenta sucintamente el sentido de la historia, el de las relaciones sociales de manera amplia y se consignan las expectativas y utopías de los campesinos en la interpretación de José.

En primer lugar, los dibujos de José Espíritu constituyen un paradigma social donde se pueden distinguir algunos temas, tales como la continuidad histórica entre el pasado y el presente, y a Jesús como el actor principal de esta historia. En el texto escrito es notoria la división entre pasado y presente, se distingue un "ayer" de un "hoy actualmente". Para marcar la diferencia, José Espíritu escribe la palabra hoy en mayor dimensión o subraya las primeras palabras de algún párrafo. En el gráfico los espacios están claramente definidos y diferenciados. La parte superior es el "ayer" y está ocupada generalmente por escenas del sacrificio de Jesús, en la parte inferior están las escenas del "hoy" y dan cuenta de la problemática campesina en sus diversas dimensiones: social, política, económica, religiosa y cultural. Durante la explicación del autor, así como en los comentarios de sus compañeros, reiteradamente se subrayan las divisiones y al mismo tiempo se destaca una continuidad, cuando dicen, por ejemplo: "Enseguida vamos a pasar a ver nuestra realidad. Pues hoy nos pasa igual a Jesús que pasó en aquel tiempo". "Ahora vamos a comparar con nuestra actualidad". "Y ahora hasta el momento sucede igual en nuestra realidad". "Y después pasamos a observar lo nuestro". "Ahora pues vamos a pasar a nuestra realidad". De este modo, el pasado no está desligado del presente y a su vez éste no es producto del azar. $\mathrm{El}$ presente, vivido como "actualmente", marca con intensidad la conciencia del modo de vida del campesino. El pasado, dicho de otra manera, no es ajeno a la vida, antes bien, forma parte de la existencia humana y de su proceso. En este horizonte no hay tiempo cíclico, se trata de un tiempo intensamente vivido y que forma parte de un tiempo de larga duración.

De hecho, Jesús de Nazaret es el sujeto que enhebra el presente con el pasado $y$ en el imaginario bambamarquino aparece 


\section{LUIS MUJICA BERMÚDEZ}

tres madres e hijos y tres crucificados. En la decimosegunda estación hay tres policías fusilando y tres crucificados. En la decimotercera hay tres cruces, tres soldados, tres mujeres alineadas, tres personajes con gorro y tres personajes representando al rico, al pobre $y$ al profesional. Por último, en la decimocuarta estación hay tres soldados "muertos" o dormidos. Se podrían asociar en el contexto religioso en que se presentan las escenas, como relacionadas a la trinidad: Dios Padre, Hijo y Espíritu Santo6.

Sin embargo, lo más importante en el dibujo son las diferencias en los tamaños de los personajes y es alli donde se muestra el poder y la estructura misma del poder. En cierto sentido, según la percepción de José Espíritu, la división social de la realidad se sintetiza en la decimotercera estación, cuando presenta tres clases sociales: el capitalista, el sector medio y el muy pobre. Además, distingue dos clases de religiosos: los protestantes y los católicos. Los "capitalistas" son "una pequeña porción de peruanos que se creen ser los unicos perfectos y justos en su sabiduría, se creen ser los unicos capaces de poder gobernar el paíz. Se creen ser los unicos que tienen derecho a comer bien, vestir bien y vivir una vida bien comoda. En sus manos de ellos está todo el poder y toda la economía del paíz. Entre ellos se pagan muy buenos sueldos para sentarse en las oficinas. Se han convertido ya en los grandes millonarios del paíz. Pero ninguno.de ellos, llega ha penzar y sentir con un corazón humano que hay muchos miles de cristianos muy pobres que vivimos moribundos aplastados por la pesada cruz que es la extrema pobreza, el hambre, la miseria, nosotros somos los sobrevivientes del tercer mundo tan solamente con el polvo de la tierra y el sudor de nuestra frente" (E6).

Esta descripción lapidaria, en resumen, presenta a los poderosos como a un "grupo cerrado" tanto en sus concepciones como en sus relaciones. Los poderosos en su mayoría aparecen con terno, corbata y anteojos. El poder religioso es identificado con los

6 Son las observaciones de Sirley Ríos, estudiante de maestría en la UNMSM, en el ensayo: "Imágenes del Otro" (enero, 2002). 


\section{REPRESENTACIÓN E IMAGINARIO CAMPESINO}

"sacerdotes", que por lo general son presentados con su vestimenta característica, con anteojos y de contextura gruesa. Pero el poder real es representado en su verdadera dimensión a través de una corona, de la que se desprenden fusiles que disparan todos los "males" (E3), como señal de que son los "poderosos" y "gobernantes" los que ocasionan los problemas que padece el campesinado. Esta idea se refuerza con la figura de un cráneo con las tibias cruzadas, símbolo de la muerte, del que pende un niño desnutrido. Al respecto los mismos campesinos dicen: "Estamos viendo una corona que representa al poder. De esta corona esta el segundo cuadro que hay un descargue de armadura de balas, donde ésta siembra miedo, siembra silencio, siembra humillación, siembra miseria, injusticia, analfabetismo, hambre, destrucción y muerte lenta. Esta descarga hacen los de poder hacia nosotros es lo que representa aquí en este cuadro" (E3).

Esta descripción hace alusión a un hecho real y representa la manifestación campesina de 1971 y la represión por parte de la policía "cuando el campesinado nos organizábamos para reclamar los derechos: es decir cuando uno veía que todo el campesinado tiene que pagar contribución, que se llama la sisa de los precios rústicos, se tenia que pagar desde las gallinas, las ovejas, el ganado inclusive de los eucaliptos, porque fueron mandados personal para que ya los enumeren a los eucaliptos pongan su número y junto a lo que tenían hacían un censo prácticamente todo lo que tenían el campesinado" (E3). Sin embargo, la opresión se representa con una crudeza extrema, con la imagen del campesino que está siendo aplastado por unas rocas echadas de una carretilla por alguien a quien no se le ve el rostro. Esta imagen es interpretada incluso como uno de las gráficos más escalofriantes, pues "está con la boca abierta, con manos extendida, es una cosa impresionantemente, aplastado... que significa que sólo la cabeza está apareciendo debajo en toda la carretilla es la que estaba trayendo que la empuja y encima de ella es porque toda la gente puede representar a éste es toda la gente representa este sufrimiento que la aplasta y la mata, que hoy está gritando realmente es cosa impresionante; que tal vez es muy difícil de distinguir pero, eso es lo que significa hoy día y es una realidad" (E2). 
Otros personajes aspirantes a la vida pública aparecen como aduladores y embaucadores, extienden la mano a siete campesinos que están de rodillas y cargando una cruz donde aparecen escritos textos como "retroceso de la Iglesia católica, críticas falsas, acusaciones, explotación, crisis económica" (E7). Además, la sexta estación, dice Candelario, "nos hace recordar muchas cosas en la vida... (los que) están con su bolsa de dinero son aquellos que ganan un buen sueldazo. En cambio los campesinos que no tienen sueldo... La ciudad tiene muchas comodidades, la luz eléctrica, las luces en las calles... en sus casas, mientras que en el campo solo hay una sola chocita donde ahí se duerme, ahí se come, se conversa, y a veces a los animalitos se cuida a un costadito... a veces no hay agua..." (E6). Es decir, en general, las autoridades están asociadas a acumulación, explotación y abuso.

Entre las autoridades religiosas se distinguen las católicos de las "sectas"; éstas son presentadas como "espiritualizantes" y poco ligadas a la realidad. De hecho, en la novena estación, por ejemplo, esta clase de autoridades aparecen rezando mientras, al parecer, los "dirigentes ronderos" son fusilados por policías. Entre las autoridades católicas pueden ser distinguidas aquellas que propiciaron el cambio de las que no han logrado continuar en la misma perspectiva y, más bien, han regresado a las prácticas preconciliares, es decir, antes de la llegada de José Dammert a Cajamarca. En la estación decimocuarta se puede ver, por eso, en el recuadro izquierdo, a los religiosos del mundo de la noche a la usanza antigua, con la Biblia en la mano y con una cruz sobre el solideo y, en el recuadro de la derecha, a los religiosos invitando junto a otros campesinos a salir al campesino de su encerramiento (E14).

La diferencia en el mundo campesino se evidencia por el poncho, el sombrero y las ojotas que usan los varones, de las mujeres que llevan mantones, polleras y sombrero y tienen los pies descalzos. Los campesinos empobrecidos no llevan sombrero y en su lugar tienen un gorro. Uno de los catequistas del lugar explica esta realidad diciendo: "En mi caso por la pobreza no puedo hacer mi sombrero y tengo que usar una gorrita que hay muchos casos diferentes que algunos llamados ya no se puede conseguir el sombre- 


\section{REPRESENTACIỌ́N E IMAGINARIO CAMPESINO}

ro.... un sombrero cuesta hasta 200 a 250 soles y un gorrito 6 a 7 soles" (E10).

Sin embargo, en la plástica de José Espíritu es muy importante la descripción de la mujer, los niños y los ancianos. En la octava estación el autor se detiene a analizar la condición de la mujer y distingue cinco "haspectos" (sic) tales como el cultural, el político, el religioso, el social y el familiar; y en la décima primera estación nuevamente retoma el tema de género presentando a la mujer como engañada, pobre, abandonada, golpeada y burlada; pues "es la que sufre en realidad más que los hombres, porque en la mujer no hay ni un minuto de descanso, a veces te toca lavar, cocinar, criar a los animales; ayuda a trabajar en la agricultura a los hombres y esto representa la señora en su trabajo en la cocina. Los hombres venimos a pedir comida, a pedir merienda; es la mujer para hacer todas estas tareas de la casa" (E8). Además, las mujeres son engañadas por los que tienen el poder; seducen a las mujeres de las organizaciones del vaso de leche, de los comedores populares, ofreciendo el "oro y el moro" y "en nuestro distrito corren sencillamente, inocentemente para dar su voto por ellos". En Bambamarca, por supuesto, sigue la situación de "la mujer usada, engañada, la madre soltera... muchas mujeres, muchachas que aparecen con bebé nunca son reconocidos los hijos por los padres" (E8). Cuando se piensa que la mujer es la que ha perdido la dignidad, José Espíritu dice que en realidad son los hombres los que han perdido su personalidad al no respetar a la mujer ofreciéndolo matrimonio y luego se la abandona con hijo, y de esta manera "todos estos problemas están haciendo desviar del verdadero camino de liberación que Jesús señala a la mujer campesina" (E10).

De hecho, los dibujos y las reflexiones de José Espíritu y la de su comunidad dicen que la mujer no valía para participar en la reunión, no se le daba importancia necesaria. Incluso en la misma Iglesia era considerada como fuente de pecado y subir al altar era considerado pecaminoso. A pesar de muchos cambios "ahora, -dice uno de ellos-, también se está repitiendo el miedo a las mujeres al tiempo de antes. Y (en el dibujo) hay un sacerdote que está con su Biblia, dice que no confíen en su pecado, más bien para que 


\section{LUIS MUJICA BERMÚDEZ}

venga a la iglesia, este lugar es muy sagrado. Entonces en estos casos se esta haciendo en la Iglesia actual" (E8).

En los dibujos de José Espíritu no aparece una imagen definida de los que pertenecen al sector medio, está bastante diluido y probablemente esté representado por los "abigeos" en la cuarta estación, en los espectadores de la séptima y el asesino de la decimosegunda estación. En todo caso, el sector medio es presentado tácitamente bajo la forma de "extranjeros" o "colaboradores". El mismo obispo Dammert no es campesino, pero lleva la ropa del campesino y de esta forma se acerca y se "encarna" en los campesinos, sin dejar su propia clase.

Como hemos visto hasta aquí, las relaciones sociales en la percepción de José Espíritu y su comunidad son desiguales, donde el abuso, la injusticia y la exclusión son elementos comunes y, puesto que al fin los poderosos "no solamente matan con fusiles, también con cuchillo y en este momento no sólo matan con armamento, sino también (con) la contaminación que están contaminando las minas, están matando libremente a las plantas, segundo a los animales, por ejemplo aquí en el río Yaucán han muerto 2000 truchas...".

Finalmente, en el imaginario campesino está presente la esperanza, a pesar de la persistencia de la pobreza y la opresión. La primera y la última estación constituyen como el comienzo y el final (telos), respectivamente, de la visión campesina; estos cuadros presentan las capacidades (Sen 2000) y la utopía de la vida campesina. Diversos factores explican la manera de ver la realidad y los cambios que se realizan. De hecho, la minga o la reciprocidad y la "luz" o la liberación son dos elementos de la misma realidad que se complementan para mostrar el horizonte de una vida distinta. Las capacidades del mundo campesino pueden encontrarse en la "compartición" (E1), en la conciencia de su propia identidad y en las marchas de reclamo y manifestación (E2 y E14).

La liberación para José Espíritu es un proceso complejo que implica tener conciencia de la realidad, sobre todo de las relaciones sociales y tener el procedimiento de reconstrucción de la relaciones. Las condiciones económicas y políticas y las relaciones sociales no se resuelven de manera rápida. Si el "poder corresponde a la capa- 


\section{REPRESENTACIÓŃ E IMAGINARIO CAMPESINO}

cidad humana, no simplemente para actuar, sino para actuar concertadamente. El poder nunca es propiedad de un individuo; pertenece a un grupo y sigue existiendo mientras que el grupo se mantenga unido" (Arendt 1973: 146), entonces, este poder tiene diversas expresiones en la vida de los campesinos. Una es la solidaridad (E1) y la otra es el sentido de justicia (10). El principio de la reciprocidad se explicita en la minga, pero también en la capacidad de rehacer las relaciones a través del perdón. El sentido de la minga es ampliamente conocido, pero no lo que significa el perdón.

Este es un procedimiento de liberación y recuperación de la persona en el contexto de la organización. Las rondas campesinas del norte no sólo servían para defenderse de los abigeos sino también para reestructurar sus formas de relación internas. Aunque en el dibujo el perdón aparece como "idealizado", no es menos cierto que ha sido uno de los procedimientos más importantes utilizados para hacer "justicia campesina". "Cuando encontramos a un hermano culpable -decía alguien- por primera vez se aconseja, por segunda vez también se aconseja, por tercera vez ahí se sanciona por medidas rápidas... pero después queda perdonado a este hermano que haya cometido algún error. Hay muchos en la mayoría de nuestras organizaciones, hermanos capaces todavía de reconocer algo malo que hayamos cometido; que somos todavía más concientes de las cosas malas que hayamos cometido. Por eso aquí estamos seguros que Jesús nos perdona, nuestro Dios y nosotros también nos perdonamos" (E10). Un campesino amigo de José Espíritu decía, por ejemplo, que en un lugar de Bambamarca "había uno que robaba y robaba, creo que lo pescaron una 2 o 3 veces creo que le dieron su fuetiada (fuete) y después le aconsejaron dejar de robar... tenía su chacrita y después posteriormente con los consejos el pidió perdón; el dijo hermanos perdónenme desde hoy voy a cambiar y se convirtió en un buen rondero y un buen dirigente. Esto nos enseña Jesús de que nos perdonemos porque a veces por falta de diálogo, por falta de conversación por falta de hablar de verdad... Pero perdonar como lo hacen los ricos creo que no lo podremos hacer" (E10).

Ahora bien, la construcción de una sociedad con paz y justicia requiere de la presencia de un conjunto de "amigos que ayudan 


\section{LUIS MUJICA BERMÚDEZ}

a los que están sufriendo". Tanto como Jesús, los campesinos tienen personajes que ayudan. Así como Simón de Cirene ayuda a Jesús, los "amigos alemanes" y José Dammert son los que colaboran y ayudan a los campesinos a liberarse. La última estación presenta la resurrección de Jesús y está muy relacionada con el "abrir los ojos". Se señala que el punto de partida de este hecho es el año 1963. Un año antes se había iniciado la renovación de la Iglesia con el concilio Vaticano II, donde José Dammert, como obispo de Cajamarca, había participado directamente como padre conciliar. Este hecho está registrado en la memoria de los campesinos de la zona y para los bambamarquinos es una fecha importante donde se comienzan a "resucitar", a "salir de la ignorancia", a "salir de la oscuridad" o a "dejar de ser ciegos". "Bueno, me parece importante el cuadro (E14) -dice Candelario-, no tengo mucho que agregar pero realmente yo quiero felicitar a Espíritu... ha sido uno de los mejores pintores con estos cuadros naturales que realmente estamos mostrando aquí, con una presencia de Jesús dentro de su pueblo. Nadie podría creerlo que Jesús usaba sombrero como la gente estaba acostumbrada a creerlo...".

\section{A MANERA DE CONCLUSIONES}

La representación y el imaginario campesino a través del dibujo, la escritura y la reflexión es una manera de dar cuenta de las percepciones del mundo social que rodea a las personas. En el caso concreto de los dibujos del vía crucis, muestra una continuidad histórica de larga duración de pobreza y dominación, de explotación y exclusión social en la imagen paradigmática de Jesús de Nazaret, que sintetiza al Cristo de la historia y los "cristos" de hoy que son los campesinos, hombres y mujeres, niños, jóvenes y ancianos de la comunidad de Bambamarca.

Las representaciones presentadas por José Espíritu suponen que los agentes de la Iglesia posconciliar han introducido algunos elementos de la modernidad que los campesinos han tomado como suyos para mostrar los avatares de su existencia. Algunos de esos elementos han permitido tomar conciencia de su dignidad y organizarse para defenderse y crecer, pero también han mostrado 


\section{REPRESENTACIÓŃN E IMAGINARIO CAMPESINO}

descarnadamente tanto los límites como las torpezas de la razón instrumental, que aparece como opresiva y excluyente. Esto quiere decir que un aspecto de la "modernidad" ha servido para conocerse a sí mismo y comprender el sentido del proceso histórico, donde el campesino aparece como sujeto. Pues el propio campesino se ha convertido en protagonista y ha logrado registrar una parte esencial de su vida e historia regional, mostrándonos en detalle su vida cotidiana.

En suma, la producción de José Espíritu representa la condición política, económica, social, religiosa y cultural de la sociedad cajamarquina. Sin embargo, no todo está dicho, la expresión de los rostros de los personajes sigue reflejando tristeza, melancolía, desesperanza, abatimiento y dolor. Incluso el Jesús campesino resucitado no aparece alegre. Esto significa que si las diversas formas de educación o formación han contribuido a tener mayor conocimiento y comprensión de sí mismo, en otro sentido no ha logrado aún la liberación en todos los aspectos y la libertad plena en la vida de la gente. A pesar de todo, tomando las palabras del mismo José Espíritu, se puede decir que, entonces, "hubo un momento en el año 1963 (que) empezó una reflexión en cadena... Y ahora... se da la organización de mujeres, hombres de jóvenes, de varones comenzando a organizarse contra la opresión, comenzando a solucionarse muchas cosas". 


\section{BibLIOGRAFÍA}

ARENDT, Hannah

1973 Crisis de la República. Taurus, Madrid.

DAMMERT BELLIDO, José.

Las notas referidas de José Dammert han sido extraídas de las cartas pastorales que se encuentran en el archivo personal del obispo, en el Instituto Bartolomé de las Casas, Lima.

BOUYSSE-CASSAGNE, Therèse y otros

1987 Tres reflexiones sobre el pensamiento andino. Hisbol, La Paz.

DE LA TORRE, Ana

1986 Los dos lados del mundo y del tiempo. Representaciones de la naturaleza en Cajamarca indígena. CIED, Lima.

EGUREN, Fernando, Cano, Janet y del Águila, Alberto 1997 Evaluación social del desarrollo humano en el Perú. Acción Ciudadana, Lima.

EQUIPO PASTORAL DE BAMBAMARCA

1977 Vamos caminando. CEP, Lima 


\section{REPRESENTACIÓN E IMAGINARIO CAMPESINO}

GITLITZ, John

199620 años de una experiencia pastoral, 1962.82. "Opción por el pobre" en Bambamarca. Impresiones Asociación Martínez Compañón, Cajamarca.

GOODY, Jack.

1999 Representaciones y contradicciones. La ambivalencia hacia las imágenes, el treatro, la ficción, la ficción, las reliquias y la sexualidad. Paidos Básico, Barcelona.

GRUZINSKI, Serge.

1991 La colonización de lo imaginario. Sociedades indígenas y occidentalización en el México español. Siglos XVI-XVIII. FCE, México.

2001 La Guerra de las imágenes. De Cristóbal Colón a 'Blade Runner' (1492-2019). FCE, México.

\section{GUTIÉRREZ, Gustavo}

1971 Teología de la liberación. Perspectivas. CEP, Lima.

1986 La verdad los hará libres. Confrontaciones. CEP-IBC, Lima.

KLINGER, Elmar, Knecht, Willi y Fuchs, Omar (Hg)

2001 Die globlale Verantwortung. Partnerschaften zwschen Pfarreien in Deutschaland und Peru. Echter, Würzburg.

LIZÁRRAGA, Karen.

1988 Identidad nacional y estética andina: una teoría peruana del arte. Concytec, Lima.

MACERA, Pablo y Andazabal, Rosaura (Recopilación).

BERROCAL EVANAN, Carmelón (Pintor-Narrador).

1999 Flora y fauna de Sarhua. Pintura y palabra. UNMSMBCRP-IFEA-ELF, Lima.

MARTÍNEZ COMPAÑÓN

1978 La obra del obispo Martínez Compañón sobre Trujillo del 


\section{LUIS MUJICA BERMÚDEZ}

Perú en el siglo XVIII. Ed. Cultura Hispánica del Centro Iberoamericano de Cooperación. Madrid. (2 tomos).

MUJICA, Luis

2005 Poncho y sombrero, alforja y bastón. El proceso pastoral de la diócesis de Cajamarca 1962-92. CEP-IBC, Lima.

NOLTE MALDONADO, Rosa María Josefa

1991 Quellcay. Arte y vida de Sarhua. Comunidades campesinas andina. Terra Nova, Lima.

OSORIO, Juan

1998 Treinta años de cambios pastorales en Bambamarca: 19631993. Tesis de maestría, PUC, Lima.

PUEBLA: Il Conferencia General del Episcopado Latinoamericano. Ed. Paulinas, Lima.

SEN, Amartya

2000 Desarrollo y libertad. Planeta, México.

SILVERMAṆ, Gail

1998 El tejido andino: un libro de sabiduría. FCE, Lima. 